\title{
GASTRIC SECRETION AFTER HISTAMINE: SODIUM AND POTASSIUM CONTENT AND PEPSIN ESTIMATION
}

\author{
By J. H. AUSTIN AND GEORGE D. GAMMON ${ }^{1}$
}

(From the Gastro-intestinal Section of Medical Clinic, University Hospital and the Department of Research Medicine, University of Pennsylvania, Philadelphia)

(Received for publication December 24, 1930)

Since Prout (1824) first demonstrated the presence of $\mathrm{HCl}$ in the gastric juice and Beaumont (1833) reported the demonstration by Dunglinson and Emmett of the bases, $\mathrm{K}, \mathrm{Na}, \mathrm{Mg}$, and $\mathrm{Ca}$, the composition of the secretion of the stomach has been repeatedly studied. The literature has been reviewed by Rosemann (1920), Carlson (1923), MacLean and Griffiths (1928), Gamble and McIver (1928), Bulger et al. (1928) and McCann (1929). The recent introduction of histamine as a stimulant of gastric secretion following the work of Popielski (1920) and the subsequent studies, reviewed by Ivy, (1930) has made it possible to secure gastric juice undiluted by test meal. Polland, Roberts and Bloomfield (1928) have demonstrated the value of measuring the rate of secretion of the constituents of the gastric juice following histamine stimulation. In their studies they measured the bases as total base. We have carried out similar studies fractionating the total base into its separate ions and report briefly our results.

From the studies in the literature it is clear that the course of gastric secretion whether stimulated by some type of test meal or by histamine is typically characterized by a rise in the curve of volume secretion associated normally in the mixed juice with rise in acid and chloride concentration, fall in sodium concentration (sodium constituting usually the larger part of the total base), approximate constancy of potassium concentration, concentrations of $\mathrm{Ca}$ and $\mathrm{Mg}$ always so small as to make difficult the measurement of their changes, fall of nitrogen concentration and change in character of the juice to a less mucoid, more watery consistency. Toward the close of the response to stimu-

${ }^{1}$ Edward W. Bok Fellow in Medicine. 
lation these changes are reversed. Fundic pouches give a similar picture but one that is free from the effects of swallowed saliva, mixture of secretion from various parts of the stomach, dilution and buffering by the test meal, and the occasional regurgitation of duodenal contents.

\section{METHODS}

In the gastro-intestinal clinic of the Hospital of the University of Pennsylvania under the direction of Dr. T. Grier Miller patients were selected who had been thoroughly studied, usually after complete gastro-intestinal $\mathrm{x}$-ray investigation. On the day of study the patient came without breakfast to the clinic. While reclining comfortably a small Rehfuss tube was cautiously introduced into the stomach and the fasting contents of the stomach removed as completely as possible by gravity and very gentle suction with a syringe. The subsequent fasting secretion collected continuously through the tube for 20 to 40 minutes was separated into samples representing 10 minute periods of collection. Either the specimens or the results of the analyses of the individual samples were combined to constitute "prehistamine" data. Histamine acid phosphate in a dose of 0.3 to $0.5 \mathrm{mgm}$. as $1: 1000$ solution of the phosphate was injected subcutaneously. Continuous removal with partition of samples at 10 minute intervals was carried out until the response was subsiding, usually after 60 to 80 minutes. Volume of secretion and acid titration were measured on each specimen. The other analyses were made on certain specimens selected with respect to the volume and acid curve, the size of the specimen, and the freedom of the specimen from blood or bile. Chlorides were measured in all of the subjects, but $\mathrm{K}, \mathrm{Na}$, and $\mathrm{N}$ only in those indicated in the tables.

Preparation. Each specimen was measured in a cylinder, and passed through ash free filter paper before sampling for analysis.

Acid titration was performed on $1 \mathrm{cc}$. samples with N/50 NaOH using Topfer's reagent to both the salmon and lemon end points, and phenolphthalein. The lemon end point of Topfer's was used in the human cases to determine the total $\mathrm{HCl}$. This has been recommended by Michaelis (1926) and our data indicate. in the human material that the sum of equivalents of total base and total $\mathrm{HCl}$ so measured approximately equals the equivalents of total chloride. It is evident that the further titration to the phenolphthalein end point represents for the most part combination of the $\mathrm{NaOH}$ with buffer substances in the specimen.

Chlorides were measured by Van Slyke's method as modified by Wilson and Ball (1928).

Phosphates were determined by an adaptation of the method of Fiske and Subbarow (1925) for total phosphorus. One cubic centimeter of juice was digested, with $2 \mathrm{cc}$. of $2.5 \mathrm{~N} \mathrm{H}_{2} \mathrm{SO}_{4}$ and the later addition of 1 drop of concentrated $\mathrm{HNO}_{3}$ in long Pyrex tubes, graduated at a volume of $10 \mathrm{cc}$. After partial dilution and 
the addition of reagents, the solution was diluted to the $10 \mathrm{cc}$. mark. The unknown was compared in a colorimeter with a standard of approximately equal strength, three standards of different strengths being employed.

Nitrogen was determined by the Kjeldahl method.

Bases were determined after ashing a sample in silica or platinum beakers with $\mathrm{H}_{2} \mathrm{SO}_{4}$ and superoxol the final stages being conducted in an electric oven at a temperature not exceeding $500^{\circ} \mathrm{C}$. After complete disappearance of carbon, 1 drop of concentrated $\mathrm{H}_{2} \mathrm{SO}_{4}$ acid was added to the ash and the heating in the oven repeated at the same temperature. The ash was dissolved in water made up to volume and aliquots taken for the following analyses.

Total base was measured by the method of Stadie and Ross (1925) on the ash from 1 cc. of juice.

Potassium was measured by the titrimetric method of Shohl and Bennett (1928) on the ash from $1 \mathrm{cc}$. of juice. Known solutions of potassium were analyzed in duplicate with each series.

Sodium was measured by the method of Barber and Kolthoff (1928) using Jena glass filtering crucibles for collection of the precipitates and employing the ash from 1 cc. of juice. Known solutions of sodium were analyzed in duplicate with each series.

Pepsin was estimated by a modification of the method of Polland and Bloomfield (1929). In their method a number of tubes each containing $300 \mathrm{mgm}$. of edestin are prepared with increasing dilution of the unknown pepsin solution to constant total volume and acidity. They are permitted to digest in a water bath at $37^{\circ} \mathrm{C}$. for the same selected time measured to the minute. At the end of the period of digestion the remaining edestin is precipitated with trichloracetic acid, its volume read after centrifugation and the amount of edestin digested is estimated by difference from blank tubes containing edestin but no pepsin. To this point we have followed their method precisely as they described it. Polland and Bloomfield then, in principle, divide the edestin digested by the amount of original pepsin solution present in the tube and plot this value, the edestin digested per unit of pepsin solution, against the dilution of the original pepsin solution in the tube. Such a plot rises to a maximum at some dilution and then, in their experience, falls. They take the edestin digested per unit of pepsin solution at the crest of this curve as a measure of the pepsin concentration of the unknown solution. We were unable to obtain reproducible estimates by this method of interpreting our data.

It is to be expected that, in the neighborhood of half digestion of the edestin, the relation of pepsin concentration to edestin digested will obey Schutz' law

$$
\log S=K+\frac{1}{2} \log E
$$

where $S$ is the amount of substrate digested, $E$ is the concentration of enzyme, and $K$ is a constant characteristic for the enzyme and substrate under constant conditions and for uniform time and temperature. 


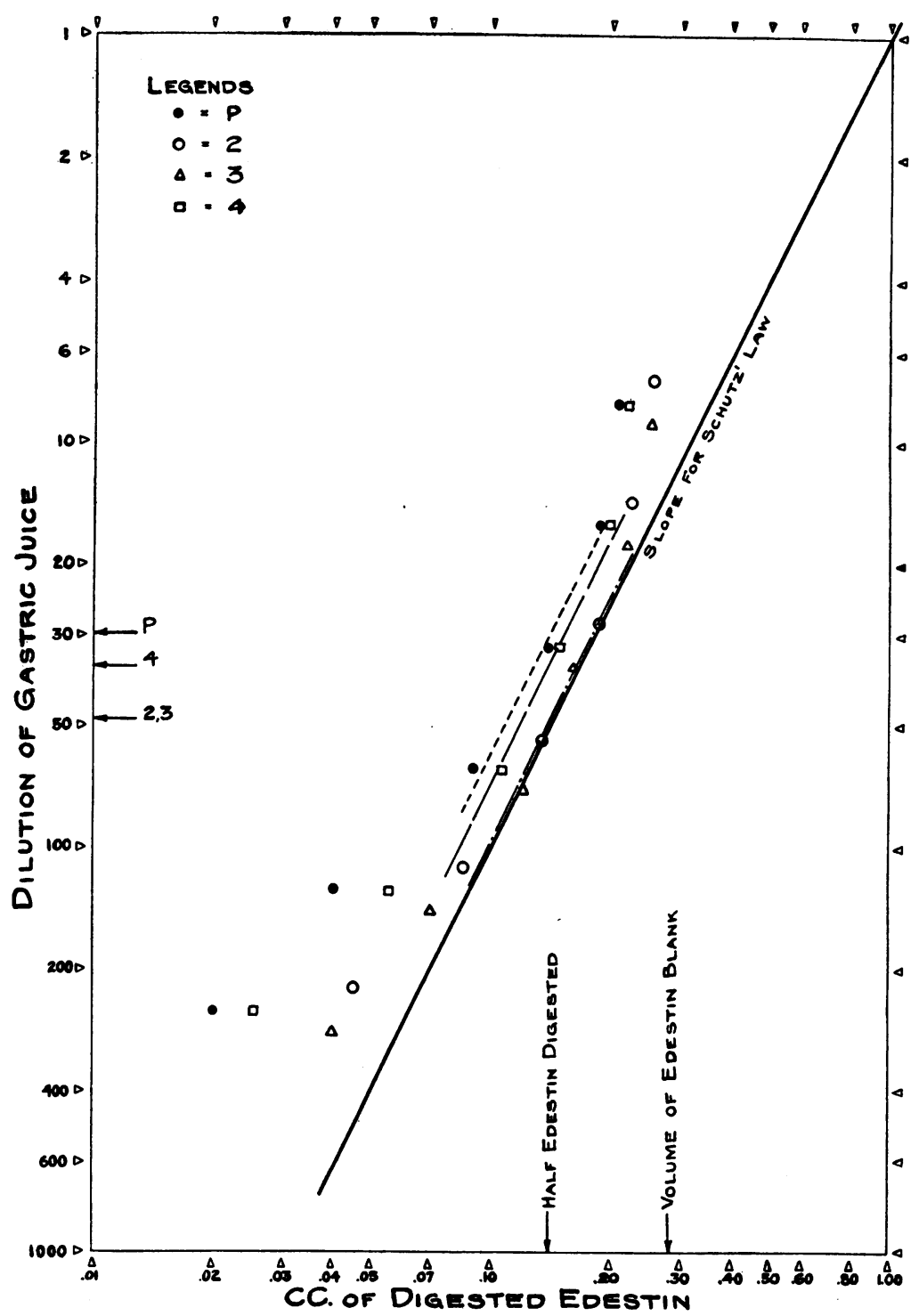

Fig. 1. Method of Interpreting Pepsin Readings (Case BR, Specimens $\mathrm{P}, 2,3$, AND 4)

For the range between 0.09 and $0.20 \mathrm{cc}$. of edestin digested (abscissae) the values for each specimen approximate the slope of Schutz' law. The intersections of these slopes with the 0.14 ordinate representing half digestion of the edestin, give the dilutions shown by arrows on the left hand margin, which are taken as proportional to the concentration of pepsin in the original specimens. 
TABLE 1

Clinical material

\begin{tabular}{|c|c|c|c|c|c|c|c|}
\hline Case & Sex & Age & Weight & $\begin{array}{c}\text { Nitro- } \\
\text { gen- } \\
\text { meas- } \\
\text { ured }\end{array}$ & Blood* & Bile* & Diagnosis \\
\hline \multicolumn{8}{|c|}{ High acid } \\
\hline & & years & pounds & & & & \\
\hline W & M. & 33 & 119 & + & & & Cholelithiasis \\
\hline$A B$ & F. & 29 & 115 & + & & & Visceroptosis \\
\hline $\mathrm{AE}$ & M. & 37 & 137 & + & Trace & & Gastric ulcer \\
\hline $\mathrm{AL}$ & M. & 44 & 115 & + & Trace 3 to 7 & + in 1 & $\begin{array}{l}\text { Arteriosclerosis, hyper- } \\
\text { tension }\end{array}$ \\
\hline AN & M. & 41 & 127 & + & Traces & +3 and 5 & $\begin{array}{l}\text { Ulcers; gastroenteros- } \\
\text { tomy; partial obstruc- } \\
\text { tion }\end{array}$ \\
\hline AO & M. & 40 & 142 & + & & +4 to 6 & Chronic constipation \\
\hline AP & M. & 37 & 145 & + & & & $\begin{array}{l}\text { Diabetes mellitus; con- } \\
\text { stipation }\end{array}$ \\
\hline$A Q$ & M. & 53 & 148 & & & & $\begin{array}{l}\text { Hyperthyroidism; BM }+ \\
39 \text { per cent }\end{array}$ \\
\hline $\mathbf{A Z}$ & F. & 25 & 114 & + & & & Chronic constipation \\
\hline BF & F. & 41 & 152 & + & & & Chronic cholecystitis \\
\hline BI & F. & 47 & 130 & + & & & Cholelithiasis \\
\hline BK & M. & 33 & 147 & + & & & Duodenal ulcer \\
\hline BP & M. & 22 & 150 & + & & +2 to 4 & Normal student \\
\hline $\mathbf{B Q}$ & M. & 59 & 150 & + & & $\begin{array}{l}+P, \text { trace } \\
\text { later }\end{array}$ & Chronic constipation \\
\hline BR & M. & 21 & 150 & + & +3 to 6 & $+\mathrm{P}$ & Normal student \\
\hline BS & M. & 24 & 132 & + & +2 to 5 & $+1,4,5$ & Normal student \\
\hline BU & M. & 23 & 140 & + & & & Normal student \\
\hline
\end{tabular}

\begin{tabular}{|c|c|c|c|c|c|c|c|}
\hline \multicolumn{8}{|c|}{ Low acid } \\
\hline B & M. & 61 & 111 & & Traces & & Tuberculosis (?); anemia \\
\hline U & M. & 53 & 158 & + & & & Arteriosclerosis \\
\hline V & M. & 23 & 150 & + & & & Duodenal ulcer \\
\hline AR & M. & 71 & 116 & & & & $\begin{array}{l}\text { Carcinoma stomach; re- } \\
\text { tention }\end{array}$ \\
\hline AT & F. & 48 & 155 & + & Traces & & Cholelithiasis \\
\hline $\mathrm{AU}$ & M. & 43 & 127 & & $\begin{array}{c}++, \text { ex- } \\
\text { cept } 4\end{array}$ & & Carcinoma stomach \\
\hline AV & M. & 62 & 190 & + & & & Chronic constipation \\
\hline BD & F. & 25 & 115 & + & & & Duodenal adhesions \\
\hline BE & M. & 48 & 147 & & & + , except 2 & Chronic arthritis \\
\hline BJ & F. & 44 & 146 & & & & Intestinal adhesions \\
\hline BO & M. & 22 & 150 & & & & Normal student \\
\hline
\end{tabular}

* Figures refer to the fractional 10 minute periods following histamine in which blood or bile appeared, $\mathbf{P}$ indicating the prehistamine period. 


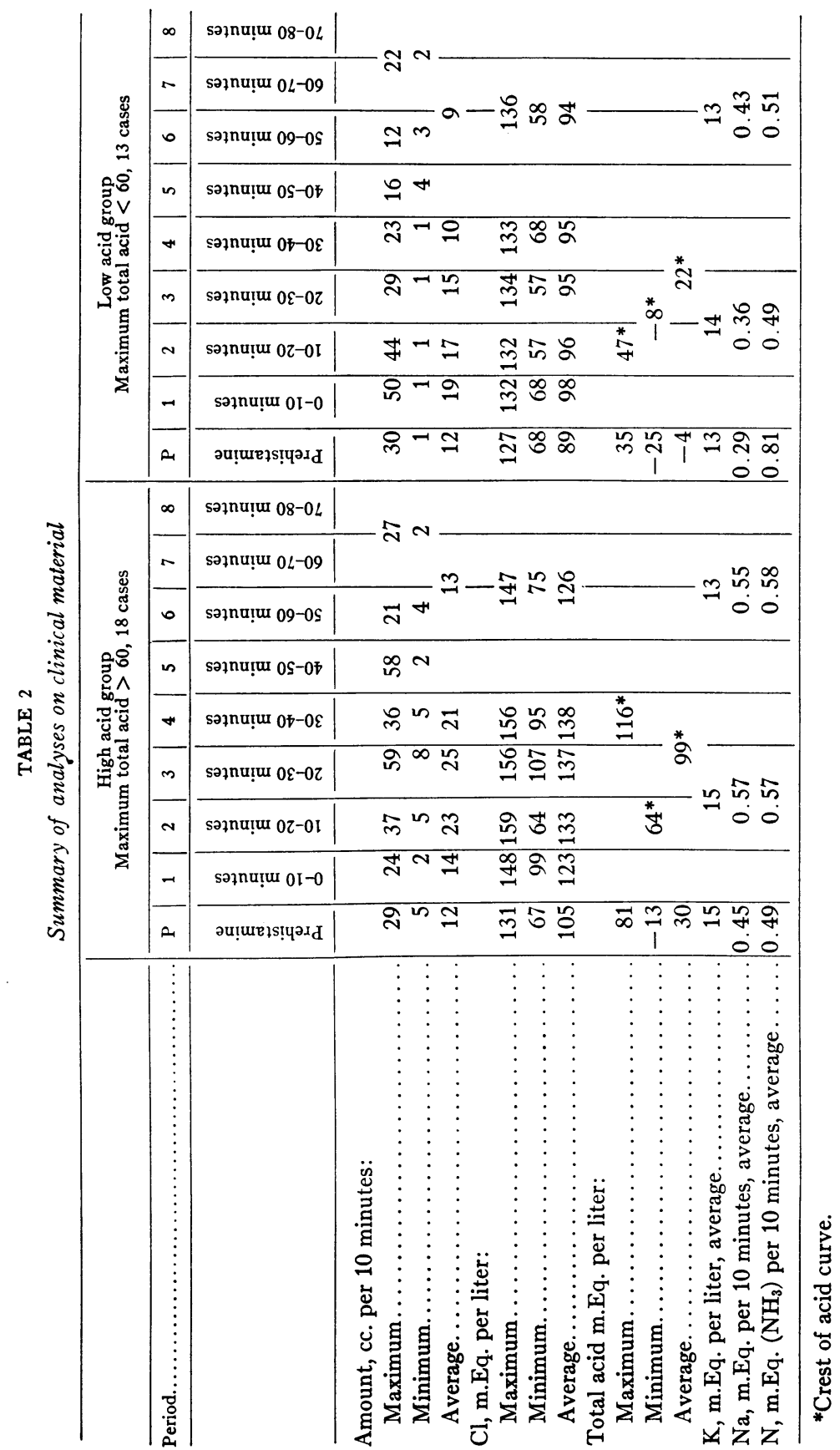


If the edestin digested be plotted on logarithmic paper against the dilution of unknown solution, then in the neighborhood of half digestion of the edestin the data should fall along a straight line whose slope is given by the equation.

TABLE 3

Potassium concentration (m.Eq. per liter)

\begin{tabular}{c|c|c|c|c|c|c|c|c|c}
\hline Case & $P$ & 1 & 2 & 3 & 4 & 5 & 6 & 7 & 8 \\
\cline { 2 - 5 } & $\begin{array}{c}\text { Prehista- } \\
\text { mine }\end{array}$ & $\begin{array}{c}0-10 \\
\text { minutes }\end{array}$ & $\begin{array}{c}10-20 \\
\text { minutes }\end{array}$ & $\begin{array}{c}20-30 \\
\text { minutes }\end{array}$ & $\begin{array}{c}30-40 \\
\text { minutes }\end{array}$ & $\begin{array}{c}40-50 \\
\text { minutes }\end{array}$ & $\begin{array}{c}50-60 \\
\text { minutes }\end{array}$ & $\begin{array}{c}60-70 \\
\text { minutes }\end{array}$ & $\begin{array}{c}70-80 \\
\text { minutes }\end{array}$ \\
\hline
\end{tabular}

High acid

\begin{tabular}{|c|c|c|c|c|c|c|c|c|c|}
\hline W & 10 & 8 & 10 & & & 10 & & & \\
\hline $\mathrm{AE}$ & 15 & 14 & & & & & & $16^{*}$ & \\
\hline $\mathrm{AL}$ & 14 & & 13 & & & & & & \\
\hline AN & 14 & & 17 & 15 & & & & 15 & \\
\hline $\mathrm{AO}$ & 10 & 14 & 18 & & & 15 & & & \\
\hline AP & 17 & 19 & 32 & & & 13 & & 14 & \\
\hline $\mathrm{AQ}$ & & & & & & & & & 14 \\
\hline $\mathrm{AZ}$ & & & 13 & & & & 14 & & \\
\hline BF & & & & & & & 13 & & \\
\hline BP & 22 & 21 & 23 & 20 & & & & & \\
\hline BQ & & & 13 & & 13 & 13 & & & \\
\hline BR & 17 & & 18 & 17 & 16 & & & & \\
\hline BS & 14 & 11 & 17 & & 15 & & & & \\
\hline BU & 17 & & & & & & & & \\
\hline
\end{tabular}

Low acid

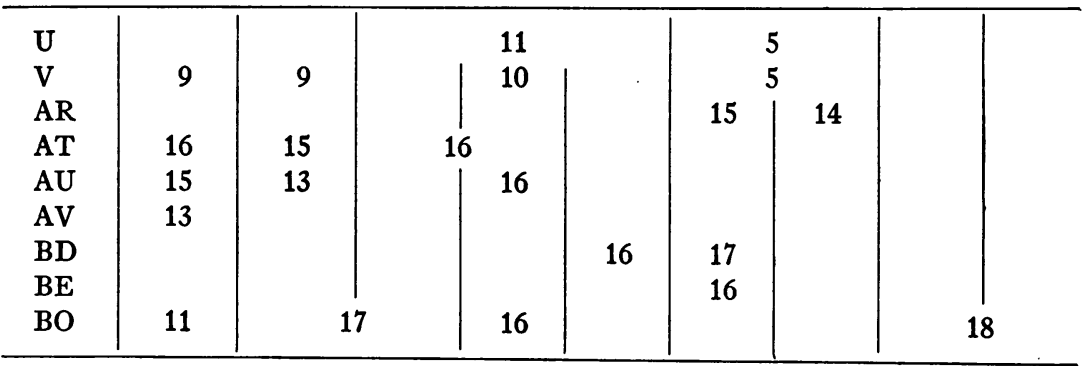

* Broken columns in this and other tables indicate a combination of material from several periods, 6,7 and 8 in this instance.

Figure 1 shows that in the neighborhood of half digestion of the edestin the observations exhibit this relationship. A line whose slope is that of the equation is accordingly drawn through the points near the locus of half digestion. The dilution indicated by this line at half digestion is taken as the concentration of pepsin in arbitrary units in the original unknown solution. 


\section{RESULTS OF CLINICAL STUDIES}

The patients studied are listed in table 1 with respect to sex, age, and diagnosis. All were used in studying volume rate of secretion, acid titration and chlorides; but only those indicated in tables 1,3 , and 4 for the measurement of $\mathrm{N}, \mathrm{K}$, and $\mathrm{Na}$. In no instances were these latter measurements made on specimens containing more than traces

TABLE 4

Sodium excretion (m.Eq. per liter)

\begin{tabular}{|c|c|c|c|c|c|c|c|c|c|}
\hline \multirow{2}{*}{ Case } & $P$ & 1 & 2 & 3 & 4 & 5 & 6 & 7 & 8 \\
\hline & $\begin{array}{l}\text { Prehista- } \\
\text { mine }\end{array}$ & $\begin{array}{c}0-10 \\
\text { minutes }\end{array}$ & $\begin{array}{c}10-20 \\
\text { minutes }\end{array}$ & $\begin{array}{c}20-30 \\
\text { minutes }\end{array}$ & $\begin{array}{c}30-40 \\
\text { minutes }\end{array}$ & $\begin{array}{c}40-50 \\
\text { minutes }\end{array}$ & $\begin{array}{c}50-60 \\
\text { minutes }\end{array}$ & $\begin{array}{c}60-70 \\
\text { minutes }\end{array}$ & $\begin{array}{c}70-80 \\
\text { minutes }\end{array}$ \\
\hline
\end{tabular}

High acid

\begin{tabular}{|c|c|c|c|c|c|c|c|c|}
\hline W & 65 & 62 & 14 & & & 20 & & \\
\hline $\mathrm{AB}$ & 64 & 70 & 35 & & 27 & 20 & & \\
\hline $\mathrm{AE}$ & 29 & 38 & & & & & 16 & \\
\hline $\mathrm{AL}$ & 80 & & 39 & & & & & 1 \\
\hline AN & 31 & & 23 & & & & & 40 \\
\hline $\mathrm{AO}$ & 42 & 38 & 22 & & & & & \\
\hline AP & 42 & 17 & 8 & & & 3 & 6 & \\
\hline BP & 19 & 14 & 4 & 2 & & & & \\
\hline $\mathrm{BQ}$ & & & 56 & & 13 & 13 & & \\
\hline $\mathrm{BR}$ & 50 & & 23 & & 8 & & & \\
\hline $\mathrm{BU}$ & 20 & & & & & & & \\
\hline
\end{tabular}

Low acid

\begin{tabular}{l|l|l|l|l|l|l|l}
\hline $\mathrm{B}$ & 49 & & & 31 & $\mid$ & $\mid$ & \\
$\mathrm{U}$ & 56 & 56 & & 29 & & 30 & \\
$\mathrm{~V}$ & 73 & 65 & & 54 & & 46 & \\
$\mathrm{BO}$ & 27 & & 32 & 24 & & $\mid$ & 37 \\
\hline
\end{tabular}

of bile or blood and usually the specimens employed were not visibly contaminated with either.

Examination of our data revealed no significant correlation with the diagnoses accepted other than the well recognized correlation of certain conditions with high or low acid titrations. Our material has been divided arbitrarily into those subjects whose maximum total $\mathrm{HCl}$ acid titration (lemon end point with Topfer's reagent) exceeded $60 \mathrm{~m}$.Eq. per liter and those failing to reach this acidity. In dealing 
with each component we direct attention either to its concentration or to its rate of secretion depending upon which proves to be as a rule the more constant through the period of response to stimulus. Following this criterion we have directed attention to the concentration of chloride and of potassium and to the rate of secretion of sodium, nitrogen, and acid. The results with respect to these.components are shown in summary in table 2, supplemented by tables 3 and 4 and

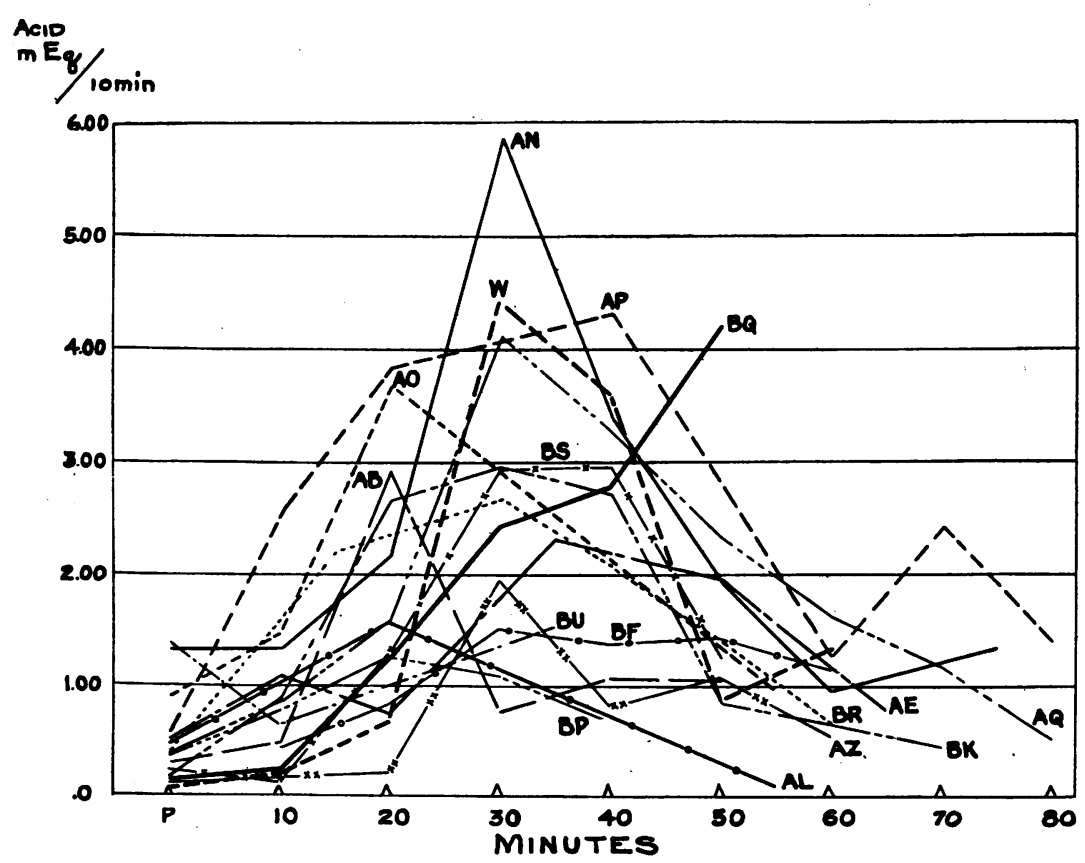

Fig. 2. Rate of Acid Secretion in High Acid Group

figures 2 to 7 , for it is clear that the significance of the course of the individual curves is somewhat masked in the presentation of table 2.

In the high acid group, the maximum response is about 30 minutes after histamine, with rise of $\mathrm{Cl}^{-}$and acid concentrations and fall of $\mathrm{Na}^{+}$and $\mathrm{N}$ concentrations. The rate of $\mathrm{Na}^{+}$and $\mathrm{N}$ secretion are usually slightly increased but the crest of these curves is earlier, usually 10 to 20 minutes after the stimulus.

In the low acid group the volume secretion rises during the first 10 
minutes, as in the high acid group, but then begins to fall off. The difference between the two groups lies not only in the marked difference

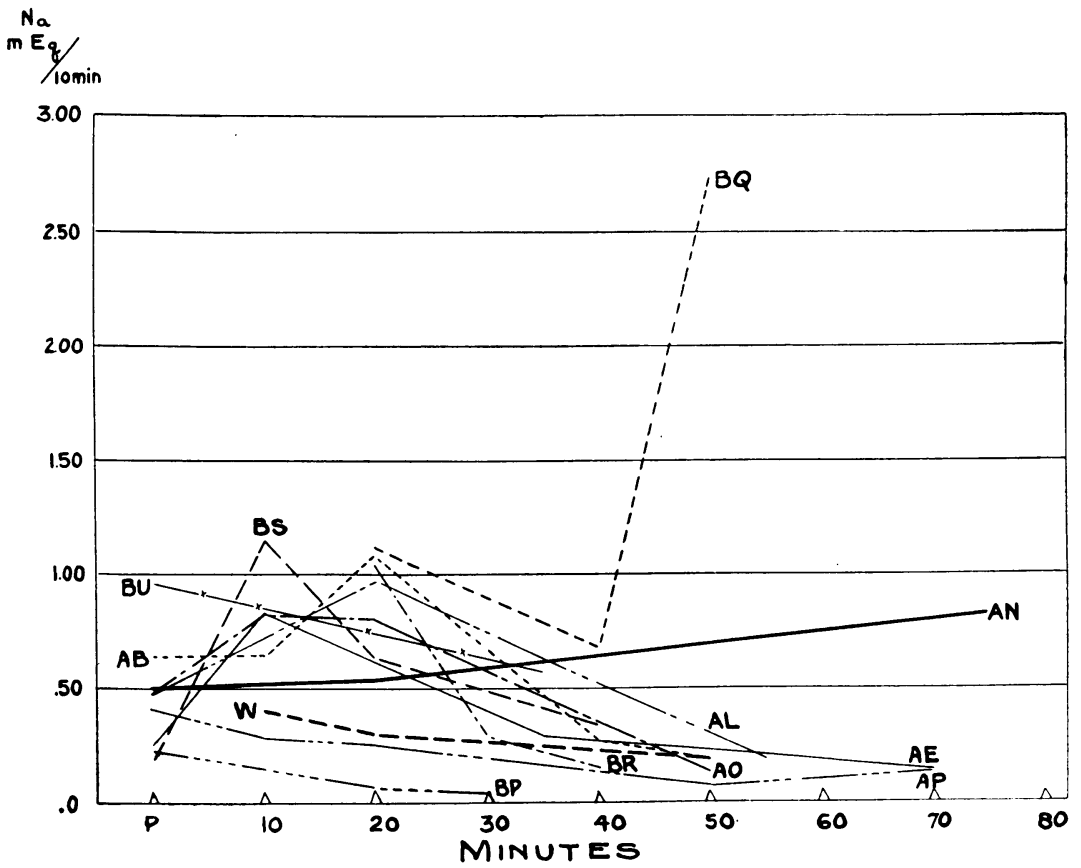

Fig. 3. Rate of Sodium Secretion in High Acid Group

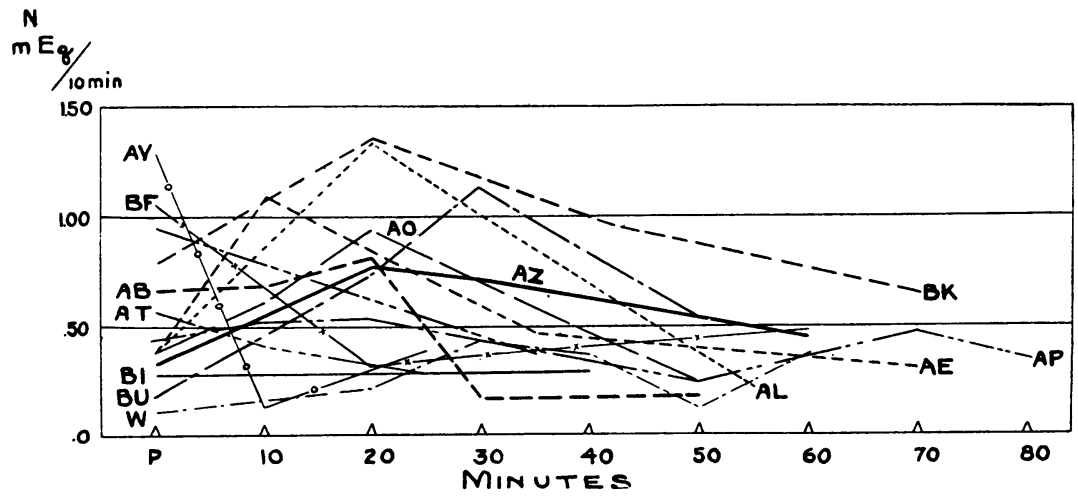

Fig. 4. Rate of Nitrogen Secretion Expressed as m.Eq. $\mathrm{NH}_{3}$ IN High Acid GROUP 


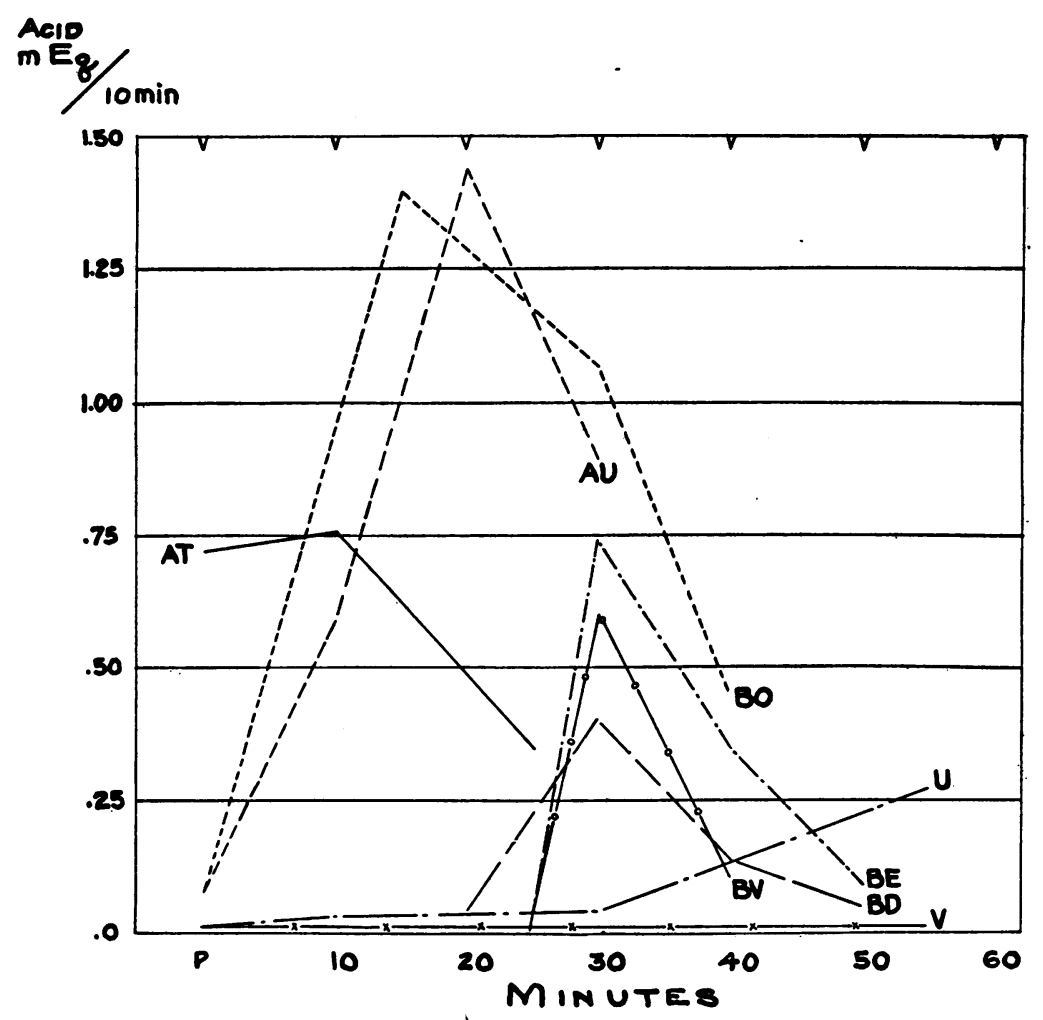

Fig. 5. Rate of Acid Secretion in Low Acid Group

Note that ordinates are on a larger scale than those of figure 2

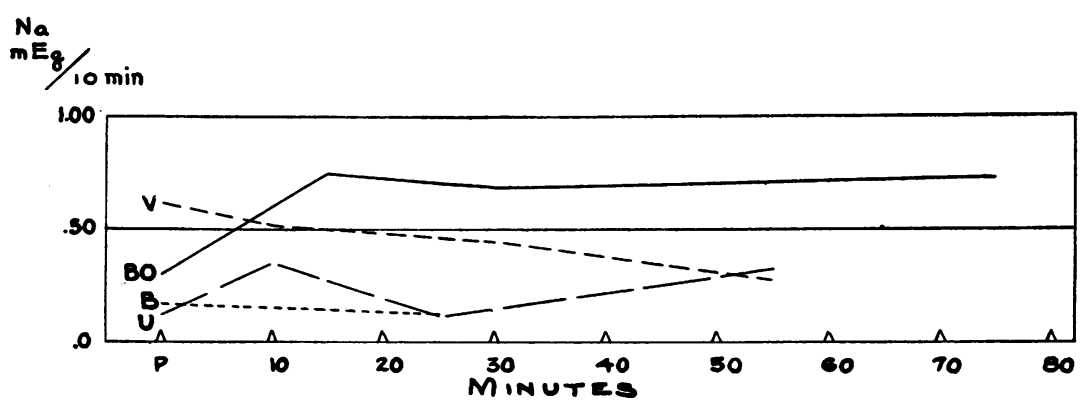

Fig. 6. Rate of Sodium Secretion in Low Acm Group 
in rate of $\mathrm{HCl}$ secretion but in less tendency to a rise in rate of secretion of $\mathrm{Na}$ and $\mathrm{N}$ in the low acid group. The correlation between $\mathrm{N}$ and $\mathrm{Na}^{+}$secretion is a rather striking one as shown in figure 8. Since in this graph rates of secretion and not concentrations are compared a misleading apparent correlation due to dilution of both by increased secretion of $\mathrm{HCl}$ is avoided.

The $\mathrm{K}^{+}$concentration is relatively constant throughout. The chloride concentration approaches at its maximum the figures of Carl-

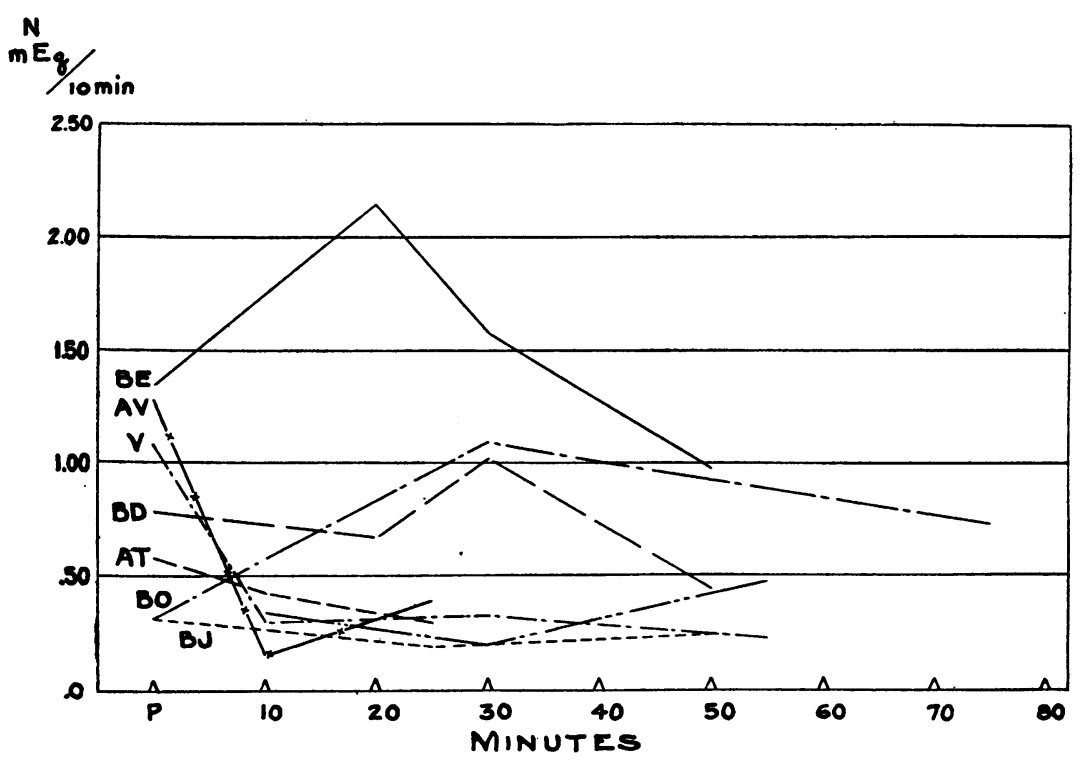

Fig. 7. Rate of Nitrogen Secretion Expressed as m.Eq. $\mathrm{NH}_{3}$ in Low Acid GROUP

son (1923) (150-165 m.Eq. per liter) on gastric fistula juice from man and of Gamble and McIver (1928) on juice from fundic pouches in dogs but never quite reaches these values. In the periods of lower stimulation, and especially in the low acid group, it may reach only 35 per cent of these values. In the low acid group, a chloride concentration as low as $64 \mathrm{~m} . \mathrm{Eq}$. per liter was observed in a subject with active secretion amounting to $31 \mathrm{cc}$. per 10 minutes. If we interpret the gastric secretion as consisting of a mixture of an acid secretion 
containing $\mathrm{HCl} 135 \mathrm{~m}$. Eq. per liter and $\mathrm{KCl} 15 \mathrm{~m}$.Eq. per liter and a second mucoid secretion containing mucus, nitrogen, and $\mathrm{NaCl}$, the evidence suggests that the $\mathrm{NaCl}$ concentrations in the mucoid secretion averages about 50 m.Eq. per liter, which is much lower than the $\mathrm{HCl}$ concentration of the acid secretion; the low acid group under this interpretation is characterized by marked depression of the $\mathrm{HCl}$ secre-

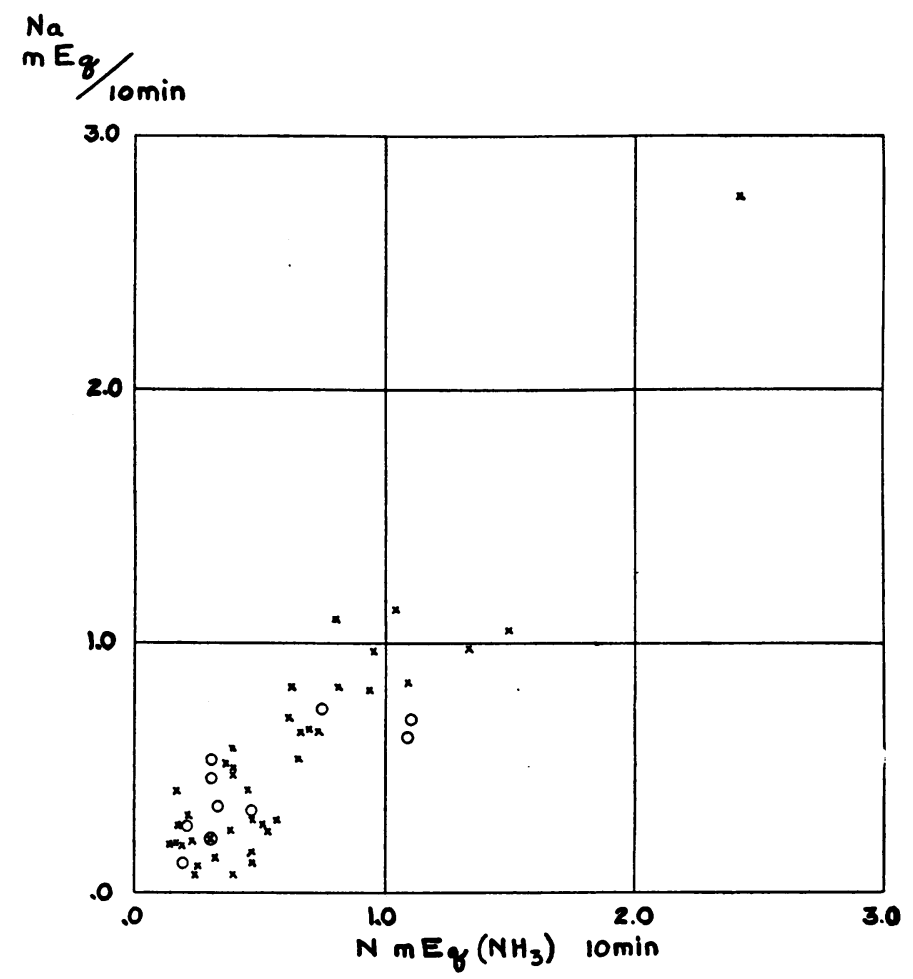

Fig. 8. Comparison of Rate of Sodium and Nitrogen Secretion in High $\operatorname{Acm}(x)$ AND Low AcID $(o)$ Groups

tion, while the mucoid secretion with its mucus, $\mathrm{N}$, and $\mathrm{NaCl}$ is only a trifle depressed. With this interpretation one would have to postulate that both secretions contain potassium in about equal concentration (10 to $20 \mathrm{~m}$.Eq. per liter) since regardless of the character of the secretion, $\mathrm{K}^{+}$concentration remains relatively constant. Our measurements of total base by the method of Stadie and Ross were compared in 51 specimens with the sum of $\mathrm{Na}^{+}$and $\mathrm{K}^{+}$measured individ- 


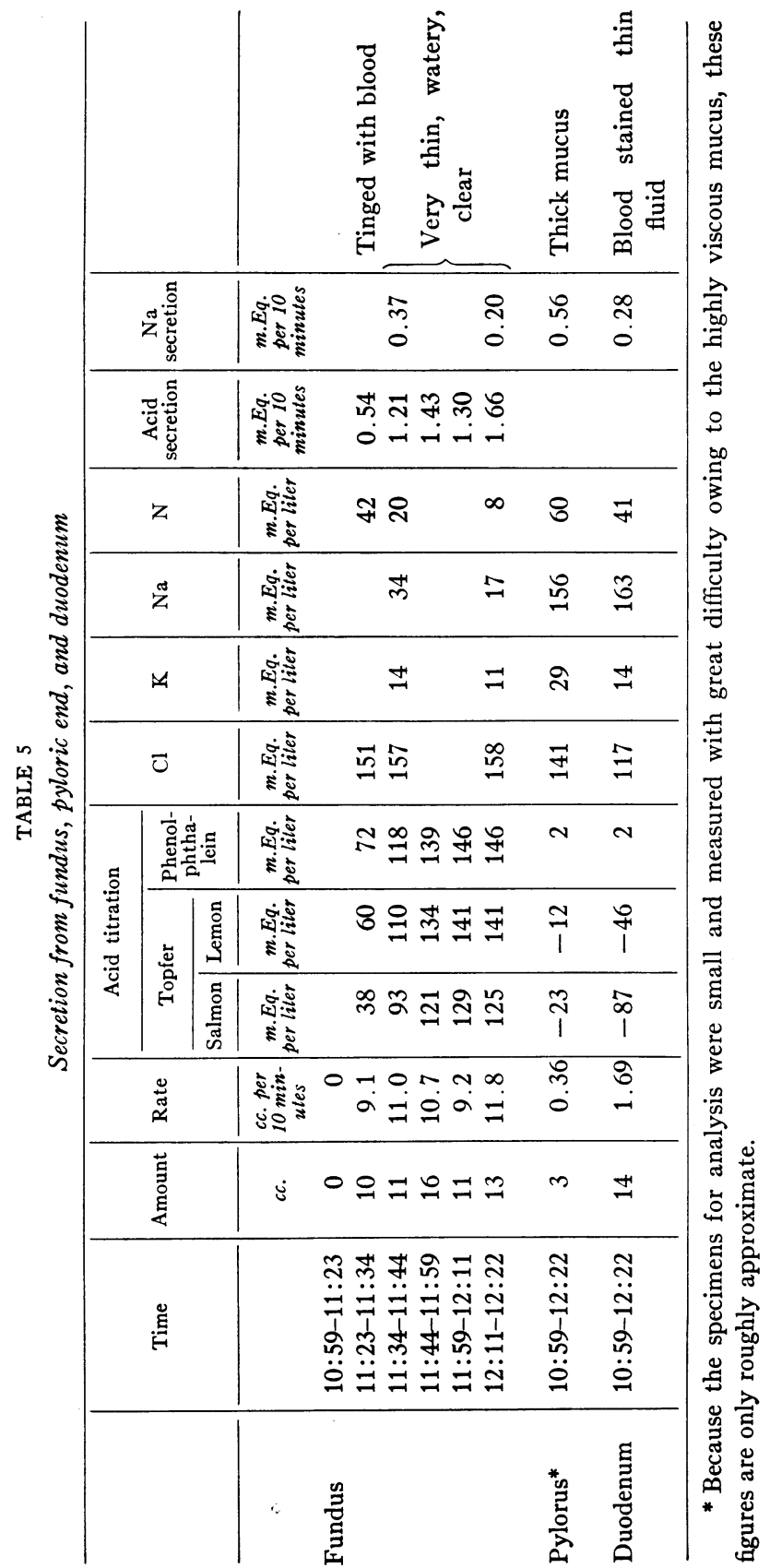


ually. The difference, which includes the sum of the errors of the three methods, ranges from -4 to $+15 \mathrm{~m}$.Eq. per liter with a mean of +4.04. This mean figure agrees approximately with the few analyses made for $\mathrm{Ca}$, giving about $2 \mathrm{~m}$.Eq. per liter, and for $\mathrm{Mg}$, giving about $1 \mathrm{~m}$.Eq. per liter. Total base concentrations in our data range from 18 to $101 \mathrm{~m}$.Eq. per liter with variations from period to period in a given fractional study of from 10 to $65 \mathrm{~m}$.Eq. per liter. Attention directed to total base concentration seems to us less illuminating than to $\mathrm{K}^{+}$concentration and rate of $\mathrm{Na}^{+}$secretion. Total phosphorus was measured in 18 specimens from 6 of the early cases studied. In 11 specimens from 3.0 to $0.2 \mathrm{mM}$ per liter of $\mathrm{PO}_{4}$ was found, and in 7, less than $0.1 \mathrm{mM}$. per liter. It was higher in the fasting contents. It was not followed further.

We have measured the pepsin concentration in several of our observations following histamine stimulation. It suffices to record that no consistent correlation of pepsin concentration with curve of secretion or acidity was observed. The pepsin concentration was as a rule more constant than either rate of secretion or acidity. Sodium concentration varied from 2 to $81 \mathrm{~m}$.Eq. per liter.

That histamine stimulates frequently the secretion of a juice high in $\mathrm{HCl}$, undiluted by test meal, is apparent both in our studies and in those of others. As will be pointed out by Gammon and Miller (1931) in a more extensive clinical study of the histamine test it is probable that the conditions of the histamine test, lacking as it does any diluting meal, do not afford opportunity for demonstrating the tendency, which Michaelis (1926) points out as characteristic of the normal stomach, of secreting enough acid to bring the $\mathrm{pH}$ of its contents to a relatively constant value, indicated by a free $\mathrm{HCl}$ of about 20 to $40 \mathrm{~m} . \mathrm{Eq}$. per liter. If this be true, a most important regulating mechanism, highly characteristic of normal gastric function, is masked under the conditions of the histamine test.

\section{EXPERTMENTAL STUDIES}

For comparison with the clinical material, we studied with the same chemical methods the secretion of fundic pouches in dogs after stimulation by food and by histamine. For the preparation of these pouches we are indebted to Dr. I. S. Ravdin, Professor of Surgical Research. 
Dog I, male, weight 13 kilos, was operated upon on October 4, 1929 by Dr. I. S. Ravdin who constructed a Pawlow pouch in the fundus of the stomach. Juice was collected during the periods of study by continuous aspiration through a fenestrated tube introduced into the pouch and leading to a collecting bottle. The animal was fed once daily on an adequate ration of casein, sugar, lard, salts, and vitavose. Weight was maintained approximately constant and the dog remained in good condition.

Three feeding experiments (IF1, IF2, and IF3) were conducted, in each of which, after commencing the collection of pouch contents, the daily feeding was given and the contents of the pouch collected, for 24 hours in the first two experiments and $10 \frac{1}{3}$ hours in the third. These experiments were conducted on November 15, November 25, 1929 and January 2, 1930. Two histamine experiments (IH1, and IH2) were conducted on November 19, and November 22, 1929. In these experiments the collection from the pouch was commenced in the fasting dog; histamine acid phosphate was injected subcutaneously. On November 19th, 5 cc. of 1:1000 solution were injected which resulted in marked conjunctival congestion and excitement; on November 22nd, $3 \mathrm{cc}$. of 1:1000 solution were injected and resulted in slight conjunctival congestion and a mild degree of restlessness. The dog drank water frequently. The collection was continued until the secretion had ceased which occurred after $3 \frac{1}{2}$ and $2 \frac{1}{2}$ hours respectively.

Dog II, male, weight 11.5 kilos, was operated upon on October 11, 1929 by Dr. I. S. Ravdin and a Heidenhain pouch constructed in the fundus of the stomach. Studies were conducted in a manner similar to those on Dog I. Two feeding experiments (IIF1 and IIF2) were performed on November 15, and 25, 1929, and a histamine experiment (IIH1) on November 22, 1929. In the latter, 3 cc. of 1:1000 solution of histamine were given subcutaneously and resulted in conjunctival congestion, mild excitement, slight incoordination, and apparent confusion.

Because of great variation in rate of secretion it was not considered practical to divide the collection over predetermined intervals. Instead the periods of collection were closed as sufficient juice for analysis had accumulated, the collecting tubes being emptied as completely as possible at the close of each period and the time of each period noted. The tabulation of the results is rendered somewhat difficult for this reason. We have accordingly prepared Chart 1 in which each of the components is presented for each period of each experiment either with respect to concentration or rate of secretion in horizontal blocks which represent the duration of the period and its location in time with respect to the stimulation by food or histamine. In only one experiment, IF3, were we able to collect any secretion before stimulation. 


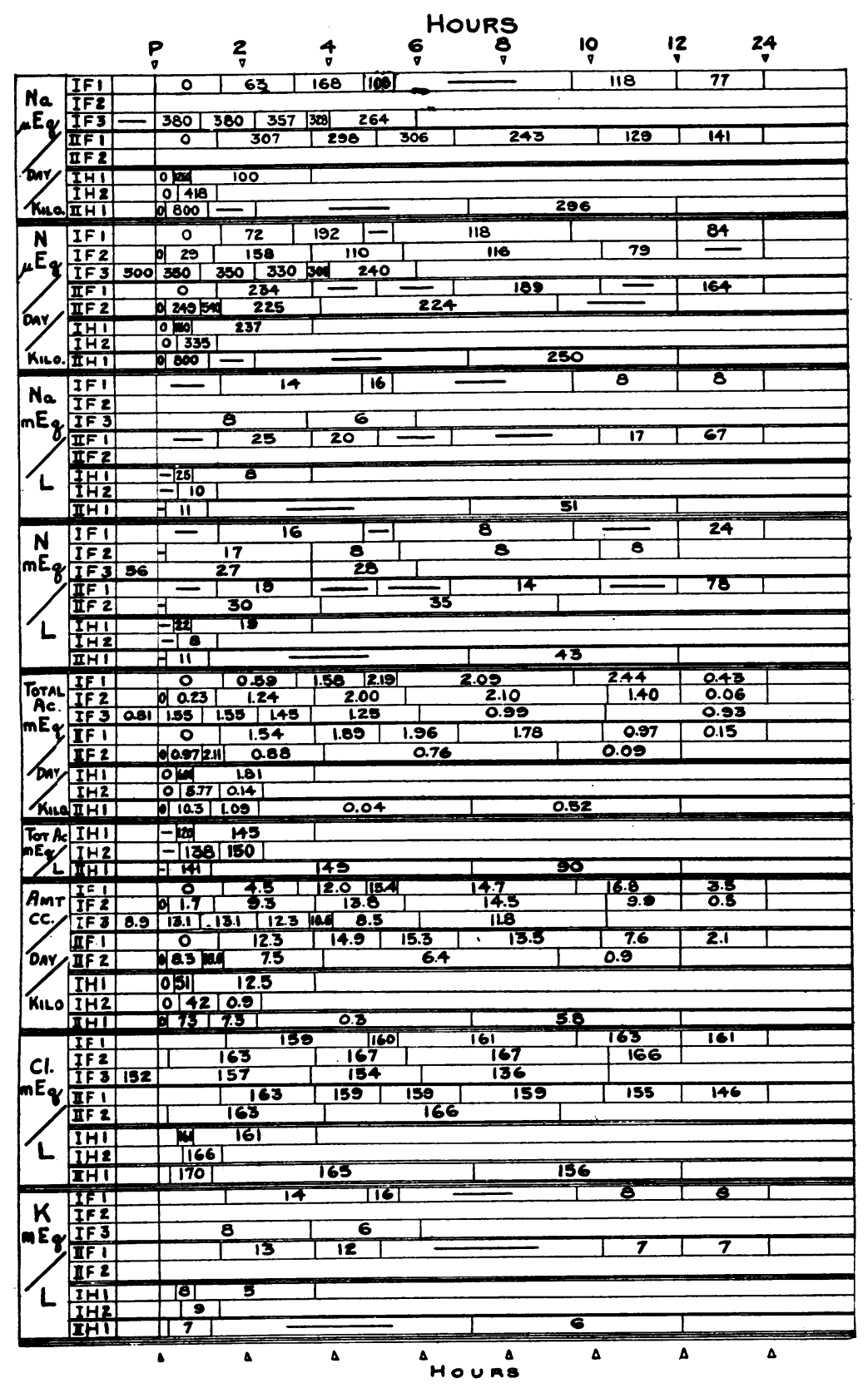

Chart 1. Experiments on Fundic Pouches in Dog I, Pawlow Pouch, and Dog II, Hemenhain Pouch

$F$ indicates stimulation by feeding; $H$, stimulation by histamine. $P$ indicates the time of stimulation. Figures show rate of excretion or concentration of the various constituents for the period in hours indicated by the position and length of the block in which the figure is placed. Zero time, " $P$," indicates the time of feeding or giving histamine. Dash in a block indicates no measurement made during that period. 


\section{RESULTS}

\section{Feeding experiments}

Rate of secretion. The secretion, except in experiment IF3, began from 10 to 90 minutes after feeding. In each animal the secretion began earlier in successive experiments, which suggests that nervous factors may have delayed the beginning of secretion in the earlier experiments. The secretion when established was of many hours duration and was usually maximal at about 4 to 10 hours after feeding.

Chloride concentration remained almost constant through most of each experiment but there was a moderate fall toward the end of two of the experiments, IF3 and IIF1.

Total $\mathrm{HCl}$ was measured to the phenolphthalein end point. Differing in this respect from our studies on human gastric juice, in the juice from the pouches the sum of the equivalents of total $\mathrm{HCl}$ measured to phenolphthalein plus equivalents of total base agreed more closely with the total chloride than did the sum of base and the total $\mathrm{HCl}$ measured to the lemon point of Topfer's indicator. Buffer substances in the juice from the pouches and in our human gastric juice would seem therefore to differ. Total $\mathrm{HCl}$ ranged in concentration from 72 to $145 \mathrm{~m} . \mathrm{Eq}$. per liter and was always above 91 in the first juice collected. Free $\mathrm{HCl}$ values were from 47 to 136 and above 68 in the first juice collected. As could be expected from the moderate variation in acid concentration the rate of acid secretion followed approximately the rate of volume secretion.

Potassium concentration when studied ranged from 6 to $16 \mathrm{~m} . \mathrm{Eq}$. per liter with a tendency to lower values toward the close of the period of secretion.

Sodium secretion followed almost the same curve as the acid and volume secretion, with a disproportionately high secretion in the resting 12 hour period studied at the end of IIF1. In this period the Na concentration was $67 \mathrm{~m}$.Eq. per liter. Otherwise the concentrations were from 6 to $25 \mathrm{~m}$.Eq. per liter.

Nitrogen secreiion was closely correlated with the $\mathrm{Na}$ secretion and both were high when the juice was conspicuously mucoid in character. 


\section{Histamine experiments}

These experiments were characterized by an extraordinarily great outpouring of secretion during the first hour at a rate three or four times the maximum attained after feeding but ceasing after $2 \frac{1}{2}$ to $3 \frac{1}{2}$ hours. The composition of the secretion was not significantly different from that which followed feeding. The earlier crest of sodium than of acid secretion which we noted in the high acid group of our clinical material is manifested by the data on Na concentration in experiment IH1 and by the fact that the maximal acid concentration occurred always in the period following the maximum rate of volume secretion and of sodium concentration and secretion.

\section{Experiment designed to separate secretion from fundus, pyloric end of stomach and duodenum}

Protocol. On April 23, 1930, a dog of about 12 kilos weight which had been fasted 12 hours was anesthetized with amytal anesthesia. At 10 A.M. the abdomen was opened. Four long-jawed clamps protected with rubber were applied to divide the lumen of stomach and duodenum into three portions, care being taken to interfere as little as possible with the blood supply. The first closed the oesophagus at its entrance to the stomach. The second divided the fundus from the pyloric end of the stomach along a line from the angulation of the lesser curvature to the junction of the splenic and pancreatico-duodenal arterial supply of the greater curvature. The third occluded the duodenum at the junction of first and second parts. The fourth was placed a little below the ampulla of Vater. The common bile duct was ligated. Bile was excluded from the duodenum, but not pancreatic juice. Three small incisions were made admitting fenestrated tubes into the fundus, the pyloric end of stomach, and the duodenum opposite the ampulla of Vater respectively. At 10.55 the stomach was emptied. At 10.59 histamine acid phosphate, $2.5 \mathrm{cc}$. of $1: 1000$ solution, was injected subcutaneously. Continuous aspiration from the three tubes was maintained until 12.22 with collection of secretion as shown in table 5. Violent peristalsis was noted in stomach and duodenum beginning about 11.02 and persisting with varying intensity for most of the experiment.

Results. In table 5 are collected the analytical data. It is evident in this experiment that the secretion from the pyloric end was negligible in quantity consisting of thick mucus. The secretion of the fundus was similar in character to that of our clinical experiments and fundus pouches. It exhibited the crest of $\mathrm{Na}$ secretion early, followed by maximal acid secretion later, as in our other experiments. 
It also showed the correlation of $\mathrm{Na}^{+}$and $\mathrm{N}$ and the more constant $\mathrm{K}^{+}$concentration.

\section{SUMMARY}

The studies presented furnish direct measurement of the rate of $\mathrm{Na}$ and $\mathrm{K}$ secretion following histamine stimulation in patients and after stimulation by both feeding and histamine in fundic pouches in dogs.

They indicate that the period of maximal sodium secretion after histamine is before the period of maximal acid secretion and not as the acid secretion is subsiding. A late increase in $\mathrm{Na}$ secretion was inferred by MacLean and Griffiths (1928) from the increase in neutral chloride in the gastric juice during subsidence of acid secretion following various types of stimulus other than histamine. The occasional increase in sodium concentration in this period in our studies is due to fall in acid secretion and not due to increased rate of sodium secretion.

The rate of nitrogen and sodium secretion in the low acid group is approximately the same as in the high acid group, not any higher.

Potassium from its constancy of concentration appears to be a constituent in about the same concentration in the gastric secretion whether this be highly acid or neutral.

The correlation in rate of secretion of sodium and of nitrogen suggests that they are constituents of one part of the gastric secretion, a part which appears to be mucoid in character.

Our results appear to be consistent with the studies of Gamble and McIver (1928) and Polland, Roberts, and Bloomfield (1928).

The course of secretion in the fundus pouches is sufficiently like that in the gastric contents of our patients to suggest that the major factor in determining the character of the gastric secretion obtained in our patients is the secretion of the fundus.

\section{BIBLIOGRAPHY}

Barber, H. H., and Kolthoff, I. M., J. Am. Chem. Soc., 1928, 1, 1625. A Specific Reagent for the Rapid Gravimentric Determination of Sodium.

Beaumont, W., Plattsburgh, 1833. See p. 78. Experiments and Observations on Gastric Juice and the Physiology of Digestion.

Bulger, H. A., Stroud, C. M., and Heidman, M. L., J. Clin. Invest., 1928, v, 547. Studies of the Chemical Mechanism of Hydrochloric Acid Secretion. I. Electrolyte Variations in Human Gastric Juice. 
Bulger, H. A., Allen D., and Harrison, L. B., J. Clin. Invest., 1928, v, 561. Studies of the Chemical Mechanism of Hydrochloric Acid Secretion. II. Observations on the Blood Passing through the Stomach of Dogs.

Carlson, A. J., Physiol. Rev., 1923, iii, 1. The Secretion of Gastric Juice in Health and Disease.

Fiske, C. H., and Subbarow, Y., J. Biol. Chem., 1925, lxvi, 375. The Colorimetric Determination of Phosphorus.

Gamble, J. L., and McIver, M. A., J. Exp. Med., 1928, xlviii, 837. The AcidBase Composition of Gastric Secretions.

Gammon, G. D., and Miller, T. G., 1931. In press. The Significance of Tests of Gastric Acidity.

Ivy, A. C., Physiol. Rev., 1930, x, 282. The Rôle of Hormones in Digestion.

MacLean, H., and Griffiths, W. J., J. Physiol., 1928, lxvi, 356. The Automatic Regulation of Gastric Acidity.

McCann, J. C., Am. J. Physiol., 1929, Ixxxix, 483. Studies on the Control of the Acidity of the Gastric Juice.

Michaelis, L., Harvey Lect., 1926-27, p. 59. Some Problems Concerning the Gastric Juice.

Polland, W. S., Roberts, A. M., and Bloomfield, A. L., J. Clin. Invest., 1928, v, 611. The Chloride, Base, and Nitrogen Content of Gastric Juice after Histamine Stimulation.

Polland, W. S., and Bloomfield, A. L., J. Clin. Invest., 1929, vii, 45. A Quantitative Method for the Estimation of Pepsin.

Popielski, L., Arch. f. d. ges. Physiol., 1920, clxxviii, 214. B-imidazolyläthylamin und die Organextrākte als mächtiger Erreger der Magendrüsen.

Prout, W., Phil. Trans. Roy. Soc., 1824, cxiv, Pt. I and II, 45. III. On the Nature of the Acid and Saline Matters Usually Existing in the Stomach of Animals.

Rosemann, R., Virch. Archiv., 1920, ccxxix, 67. Zur Physiologie und Pathologie der Säureabsonderung der Magenschleimhaut.

Shohl, A. T., and Bennett, H. B., J. Biol. Chem., 1928, Ixxviii, 643. A Micro Method for the Determination of Potassium as Iodoplatinate.

Stadie, W. C., and Ross, E. C., J. Biol. Chem., 1925, lxv, 735. A Micro Method for the Determination of Base in Blood and Serum and Other Biological Materials.

Wilson, D. W., and Ball, E. G., J. Biol. Chem., 1928, lxxix, 221. A Study of the Estimation of Chloride in Blood and Serum. 